\title{
Comprehensive analysis of a novel IncRNA profile reveals potential prognostic biomarkers in clear cell renal cell carcinoma
}

\author{
TONG LIU ${ }^{1}$, JING SUI ${ }^{1}$, YAN ZHANG ${ }^{2}$, XIAO-MEI ZHANG ${ }^{2}$, WEN-JUAN WU ${ }^{1}$, SHENG YANG ${ }^{1}$, SI-YI XU $^{1}$, \\ WEI-WEI HONG ${ }^{1}$, HUI PENG ${ }^{1}$, LI-HONG YIN ${ }^{1}$, YUE-PU PU ${ }^{1}$ and GE-YU LIANG ${ }^{1}$ \\ ${ }^{1}$ Key Laboratory of Environmental Medicine Engineering, Ministry of Education, School of Public Health, \\ Southeast University; ${ }^{2}$ Department of Oncology, Jiangsu Cancer Hospital, Nanjing, Jiangsu 210009, P.R. China
}

Received March 31, 2018; Accepted June 21, 2018

DOI: $10.3892 / o r .2018 .6540$

\begin{abstract}
Clear cell renal cell carcinoma (ccRCC) is the main subtype of malignant kidney cancer. Long non-coding RNA (lncRNA) serves a key role in predicting survival in patients with cancer. The present study aimed to develop an IncRNA-related signature of prognostic values for patients with ccRCC. RNA sequencing data of 454 patients were analyzed from The Cancer Genome Atlas (TCGA). To identify the differentially expressed IncRNAs, the patients from four groups classified by tumor stages were compared. The association between survival outcome and lncRNA expression profile was assessed by the univariate and multivariate Cox proportional hazards model. Survival was analyzed using the log-rank test, and functions of target lncRNAs were investigated through Gene Ontology and Kyoto Encyclopedia of Genes and Genomes pathway analysis. Finally, 19 lncRNAs were identified as significantly associated with overall survival (OS) time. These IncRNAs were gathered as a signal prognostic signature, which may be a potential biomarker for the prognosis of ccRCC. The risk score was built to evaluate the predictive value of the lncRNA signature. There was a significant positive correlation between ccRCC patients with the low-risk score and OS time $(\mathrm{P}<0.001)$.
\end{abstract}

Correspondence to: Dr Ge-Yu Liang, Key Laboratory of Environmental Medicine Engineering, Ministry of Education, School of Public Health, Southeast University, 87 Dingjiaqiao, Nanjing, Jiangsu 210009, P.R. China

E-mail: lianggeyu@163.com

Abbreviations: RCC, renal cell carcinomas; ccRCC, clear cell RCC; lncRNA, long-chain non-coding RNA; TCGA, The Cancer Genome Atlas; OS, overall survival; TNM, Tumor-Node-Metastasis; AUC, area under the curve; GO, Gene Ontology; ROC, receiver operating characteristic; KEGG, Kyoto Encyclopedia of Genes and Genomes; RT-qPCR, reverse transcription-quantitative polymerase chain reaction

Key words: long non-coding RNA, biomarker, clear cell renal cell carcinoma, prognosis, risk score
Reverse transcription-quantitative polymerase chain reaction (RT-qPCR) was used to verify the result in 17 pairs of ccRCC and adjacent non-tumor tissues. Functional enrichment analysis revealed that these lncRNAs were associated with several molecular pathways of the tumor. The RT-qPCR validation was consistent with the TCGA bioinformatics results. In conclusion, a tumor-specific lncRNA signature of 19 lncRNAs was identified and the joint prognostic power was evaluated in the present study, and this signature was determined to be a potential biomarker for the prognosis of ccRCC.

\section{Introduction}

Over 350,000 individuals are diagnosed with renal cell carcinomas (RCC) every year, with $\sim 140,000$ mortalities $(1,2)$. Cancer statistics from 2015 estimated that $>38,270$ males and 23,290 females were diagnosed with tumors of the kidney and renal pelvis (3). The main type of malignant kidney cancer is clear cell RCC (ccRCC), which accounts for nearly $70 \%$ of cases (4). However, relative symptoms of RCC are not obvious. To date, no precise tumor biomarkers have been found to be specific for its diagnosis or prognosis (5). RCCs can be diagnosed by imaging studies, including computed tomography and ultrasound, and a number of cases are now found on routine tests (6). RCC has a higher risk of recurring between 3-5 years after resection, and the 5-year survival rate of metastatic RCC is $<10 \%(7,8)$.

Certain biomarkers for kidney cancer have been noted in recent years. $\mathrm{B} 7 \mathrm{H} 4$ is expressed in the endothelium of tumor cells and tumor blood vessels, but not in the normal renal tissues. Therefore, low B7H4 expression is a relatively positive predictor of overall survival in patients with kidney cancer (9-11). However, high sensitivity and specific biomarkers are still lacking in patients with metastatic RCC. Therefore, the investigation of complex interactions among prognostic factors and the comprehensive evaluation based on clinical information of patients with ccRCC is crucial for the selection of treatment options and prognosis.

Due to the high specificity of long-chain non-coding RNAs (lncRNAs) in tissues, serum, plasma, urine and saliva, the focus on the study of lncRNAs in cancer continues (12). Previous 
studies showed that certain lncRNAs were also potential diagnostic and prognostic biomarkers for RCC (13-16). However, these were mainly small sample studies that concentrated on the association between a single lncRNA and prognosis. Small sample studies lack a comprehensive analysis based on large sample size genome sequencing data, which fails to explain comprehensively whether abnormal lncRNAs are associated with sex, survival or other clinical features.

In recent years, The Cancer Genome Atlas (TCGA) database has introduced a novel approach for this genomic analysis (17). The aim of the present study was to find novel lncRNA tags for the prognosis of ccRCC through data mining in TCGA database. By constructing an integrated lncRNA expression profile, combining the clinical features, a novel candidate signature was identified for the overall survival (OS) prediction of ccRCC patients.

\section{Materials and methods}

Patients and data collection. RNA sequencing data (level 3) of 537 individuals with ccRCC were extracted from TCGA (http://cancergenome.nih.gov) database up to May 26, 2016. First, the following inclusion criteria were applied: i) A histological diagnosis of ccRCC. The following exclusion criteria were then applied: i) patients with ccRCC plus other malignancies; ii) tissue samples without complete RNA sequencing data; and iii) patients who received radiotherapy and chemotherapy prior to surgery. As a result, 454 patients with RNA sequencing data and corresponding clinical features were listed. Also, the lncRNA expression profile of normal tissue samples was available in 72 patients. Based on the seventh American Joint Committee on Cancer TNM staging system (18), among all the patients, there were 209 with tumor stage I, 51 with tumor stage II, 114 with tumor stage III and 80 with tumor stage IV.

Furthermore, specimens and paired adjacent non-tumor tissues were obtained from 17 ccRCC patients from Jiangsu Cancer Hospital (Nanjing, Jiangsu, China). None of these patients have received preoperative chemoradiation. Adjacent non-tumor tissues were located $>5 \mathrm{~cm}$ away from the edge of the tumor. Tissue samples were stored in RNAlater (Ambion; Thermo Fisher Scientific, Inc., Waltham, MA, USA) and frozen at $-80^{\circ} \mathrm{C}$ until use (17). The study was approved by the Ethics Committee of Zhongda Hospital of Southeast University (Nanjing, Jiangsu, China). Informed consent was obtained from all individual participants included in the study.

Data mining and analysis of differentially expressed lncRNA. All lncRNA sequencing original reads were post-processed using TCGA RNASeqv2 system and normalized (19). In the present study, IncRNAs with their description from NCBI (https://www.ncbi.nlm.nih.gov/gene/) and Ensemble (http://www.ensembl.org/index.html) were selected for further research. To identify the expression of the different lncRNAs, the patients were divided into four clusters according to the seventh American Joint Committee on Cancer TNM staging system, and the data was compared with that of adjacent non-tumor tissues (Fig. 1). Abnormally expressed lncRNAs with level 3 RNA sequencing data were compared [fold-change,
$>2$; $\mathrm{P}<0.05$ and false discovery rate $(\mathrm{FDR})<0.05]$, and the expression status was intersected and further analyzed.

The expression profile of each IncRNA was normalized by $\log 2$-conversion, and then lncRNAs with values of 0 in $>10 \%$ of all samples were eliminated. Next, the univariate Cox proportional hazards regression model was used to analyze the association between each differentially expressed lncRNA and the OS time of patients with ccRCC. Using the multivariate Cox proportional hazards regression model, further analysis was performed to assess the prognostic value of the lncRNAs that were screened out as aforementioned (20). This study is in full compliance with NIH guidelines and TCGA data access policies.

Construction of IncRNA based prognostic biomarkers of $c c R C C$. For further analysis, a prognosis-related risk score model was developed that was based on each target lncRNA, which was weighted by a regression coefficient derived from the multivariate Cox regression model $(\beta)$ with the following formula, as previously reported $(21,22)$ : Risk score $=\exp _{\text {IncRNA1 }}$ $\mathrm{x} \beta_{\text {IncRNA } 1}+\exp _{\text {IncRNA2 }}$ x $\beta_{\text {lncRNA2 } 2}+\ldots \exp _{\text {IncRNAn }}$ x $\beta_{\text {IncRNAn }}$.

Patients were divided into two groups by the mean risk score (23). Through the Kaplan-Meier and log-rank methods (Mantel-Haenszel test), the differences between two groups were presented. Univariate Cox proportional hazards regression model and multivariate Cox proportional hazards regression model were used to further investigate the association between clinical features and OS time in patients with ccRCC. To assess the accuracy and predictive value of the risk score model, a 5-year time-dependent receiver operating characteristic (ROC) curve analysis was performed (24). The hazard ratio and $95 \%$ confidence interval were obtained. Data were assessed by Kaplan-Meier survival curves and log-rank test with IBM SPSS Statistics 21 (IBM Corp., Armonk, NY, USA).

Functional enrichment analysis. To analyze the biological features of target lncRNAs, the genes that were highly correlated with the expression of these lncRNAs (Pearson $|R|>0.5)$ in the TCGA database were investigated. Through the application of the Database for Annotation, Visualization and Integrated Discovery (https://david.ncifcrf.gov/), the Kyoto Encyclopedia of Genes and Genomes (KEGG) and Gene Ontology (GO) enrichment analyses of these lncRNAs were conducted $(25,26) . \mathrm{P}<0.05$ was considered to indicate a statistically significant difference.

Total RNA extraction and RT-qPCR verification. A total of 5 target lncRNAs were randomly selected for the verification of the reliability of the analysis by means of a random number table from Microsoft Excel software (Microsoft Corporation, Redmond, WA, USA). Total RNA was extracted from tissue samples using TRIzol reagent (Invitrogen; Thermo Fisher Scientific, Inc.). RNA purity was detected by NanoDrop 2000 spectrometer (Thermo Fisher Scientific, Inc.). According to the manufacturer's protocol, the two-step reverse transcription reactions were performed using the A214 reverse transcription system kit (GenStar, Beijing, China). RNA samples $(1 \mu \mathrm{g})$ were pre-denatured $\left(5 \mathrm{~min}\right.$ at $65^{\circ} \mathrm{C}$ and held at $\left.4^{\circ} \mathrm{C}\right)$. Next, $9 \mu \mathrm{l}$ mixture $(2 \mu 1$ 


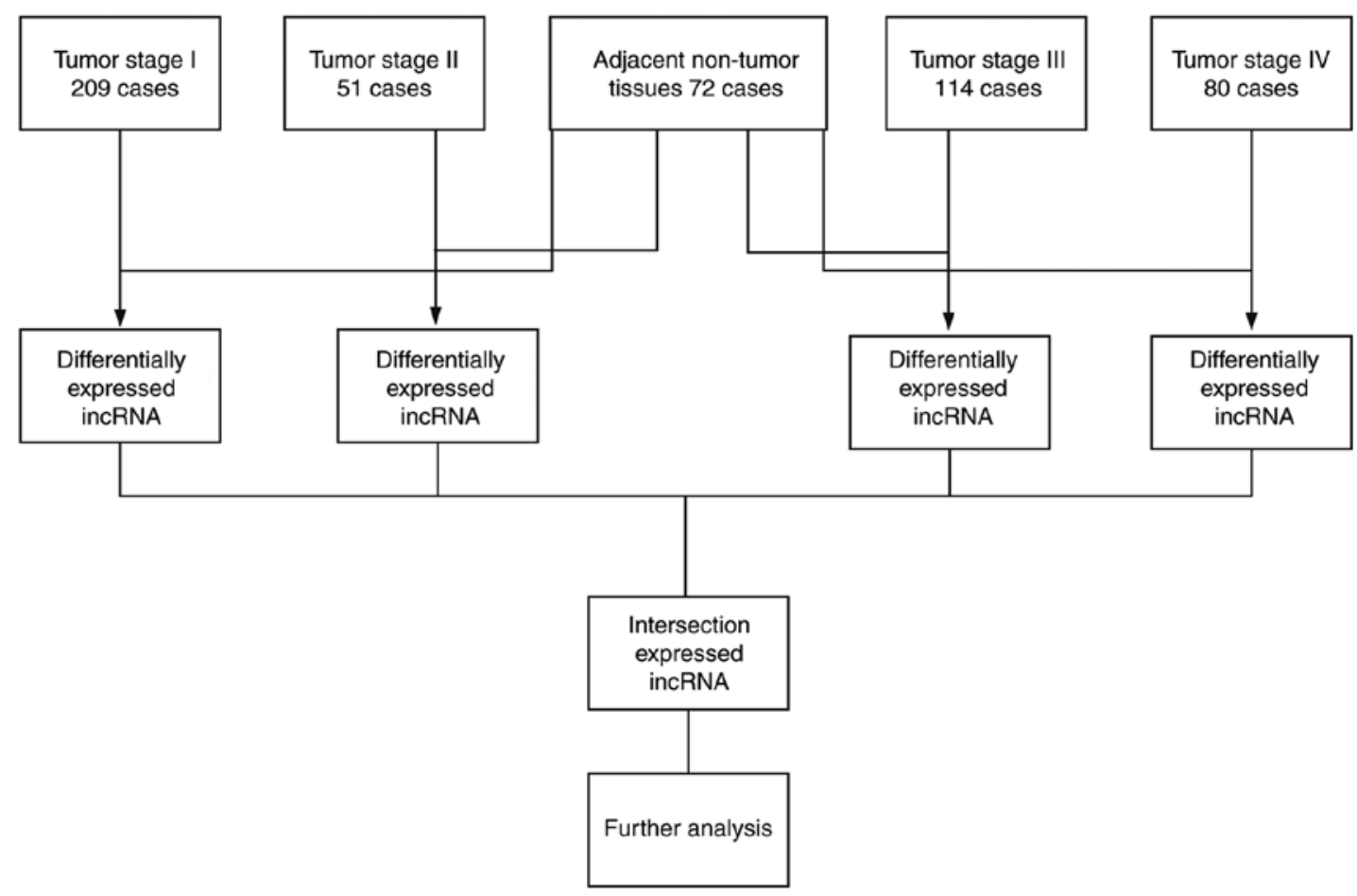

Figure 1. Flow chart of bioinformatics analysis. lncRNA, long non-coding RNA.

5X RT buffer, $0.5 \mu 1$ RT Enzyme mix, $0.5 \mu 1$ RNA-specific $\mathrm{RT}$ primers and $6 \mu \mathrm{l}$ RNase-free water) was added to $1 \mu \mathrm{g}$ pre-denatured RNA $\left(15 \mathrm{~min}\right.$ at $37^{\circ} \mathrm{C}, 5 \mathrm{~min}$ at $98^{\circ} \mathrm{C}$ and subsequently held at $4^{\circ} \mathrm{C}$ ).

qPCR was conducted to measure the expression levels of selected lncRNAs with the StepOneplus Real-Time PCR system (Applied Biosystems; Thermo Fisher Scientific, Inc.). The PCR components comprised $1 \mu \mathrm{l} \mathrm{cDNA}, 5 \mu \mathrm{l}$ Thunderbird SYBR qPCR mix, $0.3 \mu 1$ PCR primers and $3.4 \mu 1$ RNase-free water. Next, a two-step protocol $\left(95^{\circ} \mathrm{C}\right.$ for $1 \mathrm{~min}$, followed by 40 cycles of $95^{\circ} \mathrm{C}$ for $15 \mathrm{sec}, 60^{\circ} \mathrm{C}$ for $30 \mathrm{sec}$ and $72^{\circ} \mathrm{C}$ for $30 \mathrm{sec}$ ) was undertaken. All RNA primers were obtained from Generay Biotech Co., Ltd. (Shanghai, China). The primer sequences of the 5 target lncRNAs and the reference gene were as follows: COL18A1-AS1 sense, 5'-CCTCGGCCTTCCATTTCTTAA-3' and antisense, 5'-GGCGACTCACAGATGCCTTTT-3'; GK3P sense, 5'-CAACCCATTGACTTCATCACA-3' and antisense, 5'-TGCAGCTACAAGCAGACATTC-3'; TINCR sense, 5'-CCA CTGTCATCTCCCCTCTTT-3' and antisense, 5'-TCTCCCTCC CTATCTTCCATT-3'; URB1-AS1 sense, 5'-TGTTCATAACAG TCCCAAGGA-3' and antisense, 5'-AGGAGAAGACCAAAC GAAGTAA-3'; ZNF542P sense, 5'-CCTTTACCTCCTCCA TTATCC-3' and antisense, 5'-GCCTGACCTAGTTCTGCT TTT-3'; and GAPDH sense, 5'-GGACCTGACCTGCCGTCT AG-3' and antisense, 5'-GTAGCCCAGGATGCCCTTGA-3'.

Statistical analysis. The statistical significance of RT-qPCR results was analyzed by fold-change and Student's t-test using GraphPad Prism 7.0 (GraphPad Software, Inc., La Jolla, CA, USA). All data are expressed as the mean \pm standard deviation. The comparative $\mathrm{Cq}$ method was used to measure the relative expression of candidate 1 ncRNAs. The result of each sample was calculated through $2^{-\Delta \Delta \mathrm{Cq}}$ method (27): $\Delta \Delta \mathrm{Cq}=\left(\mathrm{Cq}_{\text {IncRNA }}-\mathrm{Cq}_{\mathrm{GAPDH}}\right)_{\text {tumor }}-\left(\mathrm{Cq}_{\text {lncRNA }}-\mathrm{Cq}_{\mathrm{GAPDH}}\right)$
Fold-changes were used to screen differadjacent non-tumor tissues. fold-change $>2, \mathrm{P}<0.05$ and FDR $<0.05$. The threshold of the $\mathrm{P}$-value was set as 0.05 to evaluate the null hypothesis.

\section{Results}

Patient clinical information. A total of 454 ccRCC patients and 72 normal controls with recorded clinical features were available from TCGA database. Patients were divided into four groups according to the tumor stage (I, II, III or IV). Clinical information about the patients is presented in Table I. For the total cohort, the mean age ( \pm standard deviation) was $60.209 \pm 11.909$ years. The OS time of these patients was $1,329.588 \pm 976.723$ days, and 149 out of 454 patients $(32.819 \%)$ succumbed.

Identification of differentially expressed lncRNAs. In the present study, the expression profile of 1,801 lncRNAs of ccRCC patients $(n=454)$ was compared with that of normal non-tumor tissues $(\mathrm{n}=72)$. Differently expressed lncRNAs (fold-change $>2 ; \mathrm{P}<0.05 ;$ FDR $<0.05$ ) were selected. Next, 297 lncRNAs were obtained that were differentially expressed between stage I ccRCC tumor tissues and adjacent non-tumor tissues. A total of 286 lncRNAs were differentially expressed between stage II ccRCC tumor tissues and adjacent non-tumor tissues, 332 lncRNAs were differentially expressed between stage III ccRCC tumor tissues and adjacent non-tumor tissues, and 337 lncRNAs were differentially expressed between stage IV ccRCC tumor tissues and adjacent non-tumor tissues. Finally, 247 overlapping differentially expressed lncRNAs were selected for further analysis (Fig. 2).

Using the univariate Cox proportional hazards regression model, results of the comprehensive analysis of 
Table I. Clinical features of clear cell renal cell carcinoma patients $(n=454)$ from TCGA database.

\begin{tabular}{ll}
\hline Variables & Patients, $\mathrm{n}$ \\
\hline
\end{tabular}

\section{Ethnicity}

Caucasian

African descent

Asian

Sex

Female

Male

Age, years

$\leq 65$

$>65$

TNM stage

I

II

III

IV

T stage

T1

$\mathrm{T} 2$

T3

T4

$\mathrm{N}$ stage

N0

N1

M stage

M0

M1

Histological stage

G1

G2

G3

G4

Laterality

Left

Right

Primary treatment outcome

CR

PR

SD

PD

Person neoplasm cancer status

Tumor-free

With tumor

Neoadjuvant treatment

Yes

No

Hemoglobin result

Low

Normal

Elevated
Table I. Continued

\begin{tabular}{lc}
\hline Variables & Patients, $\mathrm{n}$ \\
\hline Serum calcium result & 169 \\
Low & 130 \\
Normal & 9 \\
Elevated & \\
White cell count result & 7 \\
Low & 232 \\
Normal & 132 \\
Elevated & \\
\hline
\end{tabular}

RNA sequencing data was downloaded for $454 \mathrm{ccRCC}$ patients from TCGA database, however, not all had complete clinical information. $\mathrm{CR}$, complete remission; $\mathrm{PR}$, partial remission; SD, stable disease; PD, progressive disease; TNM, Tumo-Node-Metastasis; TCGA, The Cancer Genome Atlas.

247 differentially expressed lncRNAs and clinical information from TCGA database indicated that 106 lncRNAs were significantly associated with OS time $(\mathrm{P}<0.05)$. Next, using the multivariate Cox proportional hazards regression model, the association between the aforementioned lncRNAs and the OS time of ccRCC patients was calculated. Finally, 19 intersecting key lncRNAs (LOC606724, SCART1, SNORA8, LOC728024, HAVCR1P1, FCGR1CP, LINC00240, LINC00894, GK3P, SNHG3, KIAA0125, URB1-AS1, ZNF542P, TINCR, LINC00926, PDXDC2P, COL18A1-AS1, LINC00202-1, and LINC00937) were identified to be significantly associated with OS time $(\mathrm{P}<0.05)$, which was an independent biomarker (Table II).

Construction of an lncRNA-based prognostic signature. Next, the risk score model for predicting OS time was constructed with the following formula: Risk score $=(\operatorname{expLOC606724}$ $\mathrm{x}-0.639)+(\operatorname{expSCART} 1 \mathrm{x}-0.941)+(\operatorname{expSNORA} 8 \times 0.693)$ $+(\operatorname{expLOC728024x-0.495)+(\operatorname {expHAVCR}1\mathrm {P}1\times 0.670)}$ $+(\operatorname{expFCGR1CP} \times 0.568)+(\operatorname{expLINC00240\times -0.575)}+$ $(\operatorname{expLINC00894} \times 0.803)+(\operatorname{expGK3P} \times-0.770)+(\operatorname{expSNHG} 3$ $\mathrm{x} 0.682)+(\operatorname{expKIAA0125} \mathrm{x}-0.431)+(\operatorname{expURB1AS} 1 \mathrm{x}$ $0.774)+(\operatorname{expZNF542P} \times-0.537)+(\operatorname{expTINCR} \times 0.843)$ $+(\operatorname{expLINC00926\times 0.930)}+(\operatorname{expPDXDC} 2 \mathrm{P} \times-0.929)+$ $(\operatorname{expCOL18A1AS1~x~-0.594)~+~(expLINC002021~x~-0.577)~+~}$ (expLINC00937 x 0.806). Based on the risk score, patients were separated into two groups (high-risk group, $n=227$, and low-risk group, $n=227$ ) through the cut-off value of the median risk score (Fig. 3). Results showed that the area under the curve (AUC) was 0.718 (Fig. 4A), which verified the predictive value of the aforementioned risk score. The Kaplan-Meier curve indicated that the survival time of the patients in the low-risk score group $(1,425.996 \pm 1,000.008$ days) was longer than that of the patients in the high-risk score group $(1,233.181 \pm 945.223$ days $)$ $(\mathrm{P}=0.001$; Fig. 4B).

Additionally, to verify whether the prognostic value of the constructed lncRNA signatures was independent of other clinical characteristics, the risk score and other clinical features were systematically analyzed using the univariate 
Table II. Prognostic value of the differentially expressed lncRNAs according to multivariate cox regression analysis.

\begin{tabular}{|c|c|c|c|c|c|}
\hline IncRNA & Estimate & StdErr & $\chi^{2}$ & P-value & $\operatorname{HR}(95 \% \mathrm{CI})$ \\
\hline LOC606724 & -0.639 & 0.250 & 6.517 & $0.011^{\mathrm{a}}$ & $0.528(0.323-0.862)$ \\
\hline SCART1 & -0.941 & 0.299 & 9.887 & $0.002^{\mathrm{a}}$ & $0.390(0.217-0.702)$ \\
\hline SNORA8 & 0.693 & 0.311 & 4.957 & $0.026^{\mathrm{a}}$ & $1.999(1.086-3.678)$ \\
\hline LOC728024 & -0.495 & 0.209 & 5.614 & $0.018^{\mathrm{a}}$ & $0.610(0.405-0.918)$ \\
\hline HAVCR1P1 & 0.670 & 0.196 & 11.689 & $0.001^{\mathrm{a}}$ & $1.954(1.331-2.869)$ \\
\hline FCGR1CP & 0.568 & 0.209 & 7.365 & $0.007^{\mathrm{a}}$ & $1.766(1.171-2.662)$ \\
\hline LINC00240 & -0.575 & 0.208 & 7.652 & $0.006^{\mathrm{a}}$ & $0.563(0.374-0.846)$ \\
\hline LINC00894 & 0.803 & 0.358 & 5.033 & $0.025^{\mathrm{a}}$ & $2.232(1.107-4.503)$ \\
\hline GK3P & -0.770 & 0.233 & 10.863 & $0.001^{\mathrm{a}}$ & $0.463(0.293-0.732)$ \\
\hline SNHG3 & 0.682 & 0.255 & 7.173 & $0.007^{\mathrm{a}}$ & $1.979(1.201-3.260)$ \\
\hline KIAA0125 & -0.431 & 0.206 & 4.350 & $0.037^{\mathrm{a}}$ & $0.650(0.434-0.974)$ \\
\hline URB1AS1 & 0.774 & 0.200 & 15.031 & $0.000^{\mathrm{a}}$ & $2.168(1.466-3.207)$ \\
\hline ZNF542P & -0.537 & 0.215 & 6.264 & $0.012^{\mathrm{a}}$ & $0.584(0.384-0.890)$ \\
\hline TINCR & 0.843 & 0.216 & 15.302 & $0.000^{\mathrm{a}}$ & $2.323(1.523-3.544)$ \\
\hline LINC00926 & 0.930 & 0.261 & 12.673 & $0.000^{\mathrm{a}}$ & $2.535(1.519-4.232)$ \\
\hline PDXDC2P & -0.929 & 0.360 & 6.664 & $0.010^{\mathrm{a}}$ & $0.395(0.195-0.800)$ \\
\hline COL18A1AS1 & -0.594 & 0.202 & 8.685 & $0.003^{\mathrm{a}}$ & $0.552(0.372-0.820)$ \\
\hline LINC002021 & -0.577 & 0.290 & 3.952 & $0.047^{\mathrm{a}}$ & $0.561(0.318-0.992)$ \\
\hline LINC00937 & 0.806 & 0.251 & 10.335 & $0.001^{\mathrm{a}}$ & $2.239(1.370-3.659)$ \\
\hline
\end{tabular}

${ }^{\mathrm{a}} \mathrm{P}<0.05$. lncRNA, long non-coding RNA; HR, hazard ratio; CI, confidence interval; StdErr, standard error.

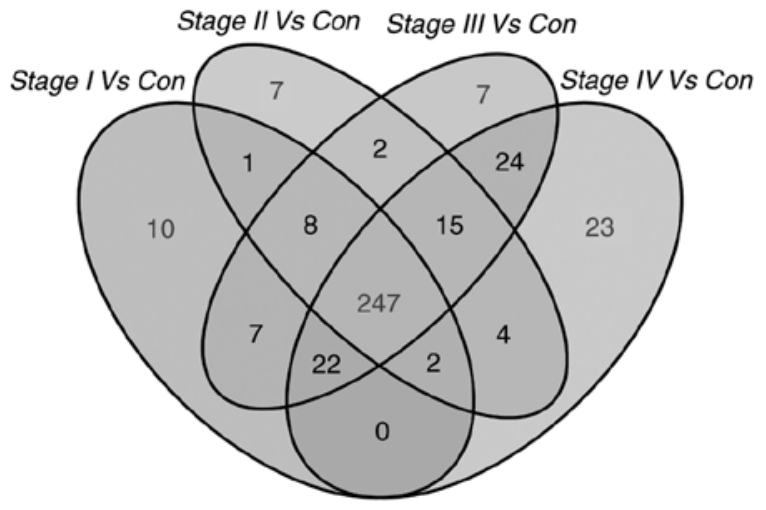

Figure 2. Venn diagram analysis of differentially expressed long non-coding RNAs in clear cell renal cell carcinoma. Each ellipse represents a tumor-stage group. The value in the middle represents significant and consistent differential expression in all four groups. Con, control.

Cox proportional hazards regression model and the multivariate Cox proportional hazards regression model. The clinical characteristics of age, TNM stage according to the seventh American Joint Committee on Cancer TNM staging system (1), T stage, $\mathrm{N}$ stage, $\mathrm{M}$ stage, laterality, neoplasm cancer, the elevated serum calcium result, neoadjuvant treatment, hemoglobin result and risk score, all showed some predictive value through the univariate Cox proportional hazards regression analysis. However, following the analysis of the multivariate Cox proportional hazards regression model, only the neoplasm cancer $(\mathrm{P}<0.001)$ and risk score $(\mathrm{P}=0.004)$ were independent prognostic factors of ccRCC (Table III).
Kaplan-Meiercurvesrevealed thatclinicalfeatures,including age $(>65$ years) $(\mathrm{P}<0.001)$, TNM stage $(\mathrm{III}+\mathrm{IV})(\mathrm{P}<0.001)$, $\mathrm{T}$ stage $(\mathrm{III}+\mathrm{IV})(\mathrm{P}<0.001), \mathrm{N}$ stage $(\mathrm{N} 1)(\mathrm{P}<0.001), \mathrm{M}$ stage (M1) $(\mathrm{P}<0.001)$, laterality $(\mathrm{P}=0.036)$, neoplasm cancer (with tumor) $(\mathrm{P}<0.001)$, neoadjuvant treatment (yes) $(\mathrm{P}=0.008)$, hemoglobin result (abnormal) $(\mathrm{P}<0.001)$ and risk score (high) $(\mathrm{P}<0.001)$, were significantly associated with poor OS time (Fig. 5). To evaluate the predictive power of the risk score model (AUC=0.718), the prognostic value of other clinical features was compared (Fig. 6). Results indicated that the risk score conferred a prognostic value for prediction.

Functional enrichment analysis. In total, 1,149 genes were identified from TCGA database, which were co-expressed with the aforementioned 19 lncRNAs (Pearson $|R|>0.5$ ). A total of 62 pathways were indicated by KEGG analysis, and 222 GO terms $(\mathrm{P}<0.05$ and enrichment $>2)$ were identified by enrichment of these genes. The result revealed that the highest enriched GO terms were 'regulation of transcription, DNA-dependent' (GO: 0006355), 'transcription, DNA-dependent' (GO: 0006351) and 'small molecule metabolic process' (GO: 0044281) (Fig. 7A). Furthermore, KEGG analysis indicated that the most significant pathways of co-expressed genes were 'metabolic pathways' (path ID: 01100), 'carbon metabolism' (path ID: 01200) and 'glycerophospholipid metabolism' (path ID: 00564) (Fig. 7B).

$R T-q P C R$ verification. To verify the bioinformatics analysis results, 5 lncRNAs were randomly selected and their expression was analyzed in 17 pairs of ccRCC tissue samples. The 
A

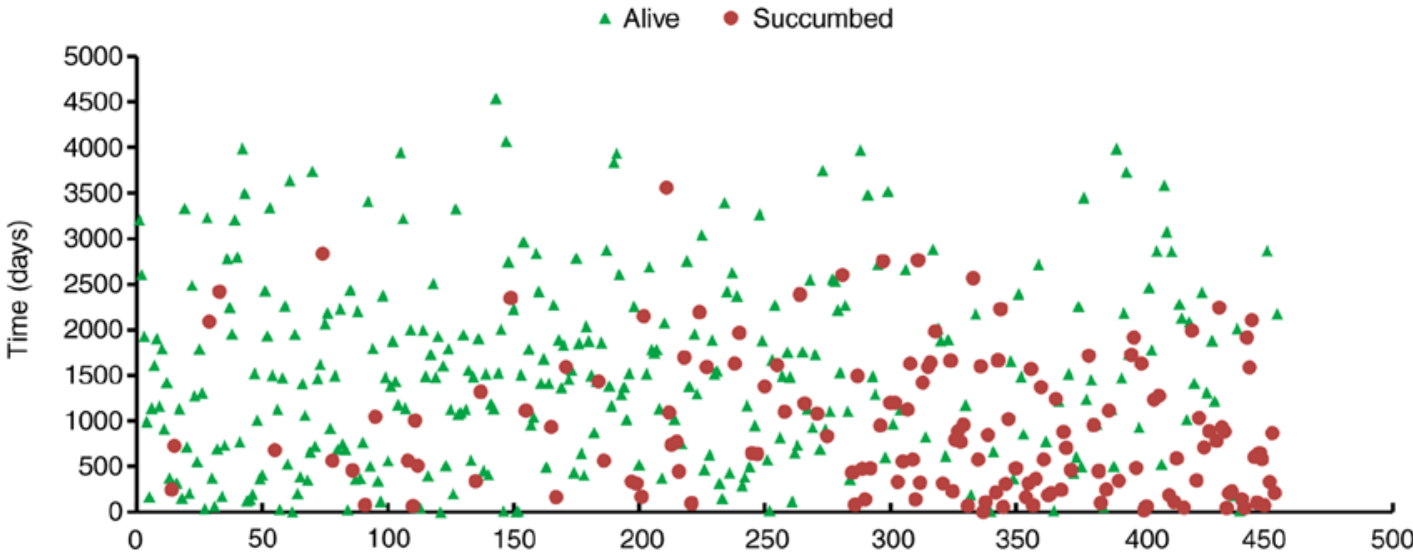

B
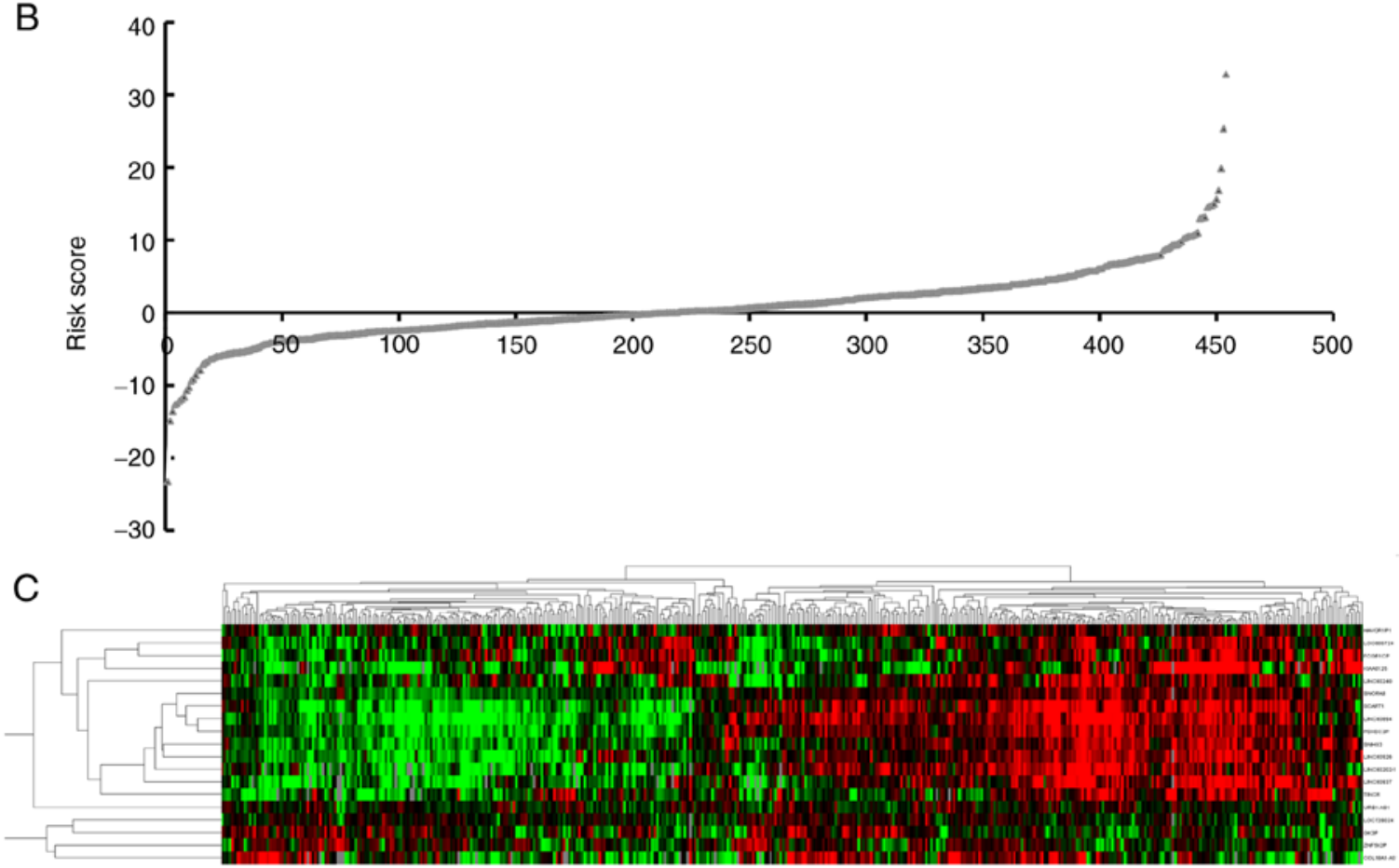

Low risk score

High risk score

Figure 3. Risk score analysis of the differentially expressed lncRNA signature of clear cell renal cell carcinoma. (A) Survival status and duration of cases; (B) risk score of IncRNA signature; and (C) low and high score groups for the 19 lncRNAs. IncRNA, long non-coding RNA.
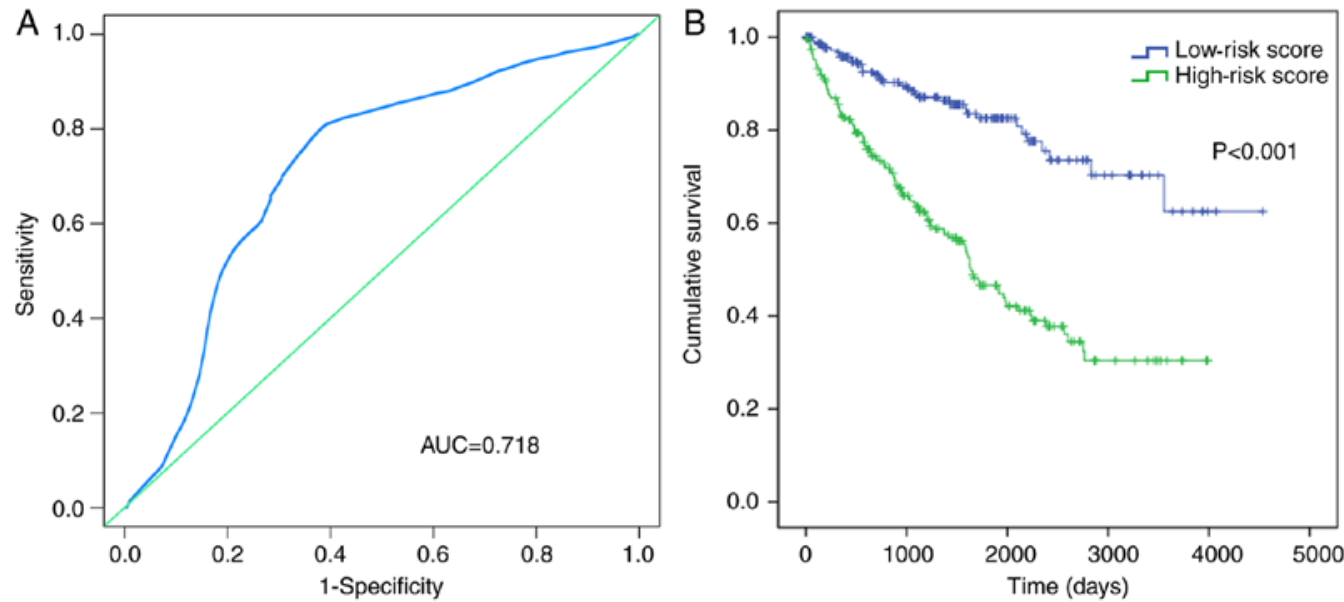

Figure 4. Signature of 19 differentially expressed long non-coding RNAs of clear cell renal cell carcinoma with regard to outcome. (A) The risk score is shown by the time-dependent receiver operating characteristic curve for predicting 5-year survival. (B) The Kaplan-Meier test of the risk score for overall survival. AUC, area under the curve. 
Table III. Predicted values of clinical features and risk score.

\begin{tabular}{|c|c|c|c|c|}
\hline \multirow[b]{2}{*}{ Variables } & \multicolumn{2}{|l|}{ Univariate analysis } & \multicolumn{2}{|c|}{ Multivariate analysis } \\
\hline & $\mathrm{HR}(95 \% \mathrm{CI})$ & P-value & HR $(95 \% \mathrm{CI})$ & P-value \\
\hline \multicolumn{5}{|l|}{ Ethnicity } \\
\hline Caucasian & 1.000 (reference) & & & \\
\hline African descent & $1.179(0.617-2.252)$ & 0.617 & & \\
\hline Asian & $0.532(0.074-3.811)$ & 0.529 & & \\
\hline \multicolumn{5}{|l|}{ Sex } \\
\hline Male & 1.000 (reference) & & & \\
\hline Female & $0.899(0.646-1.249)$ & 0.525 & & \\
\hline \multicolumn{5}{|l|}{ Age, years } \\
\hline$\leq 65$ & 1.000 (reference) & & & \\
\hline$>65$ & $1.804(1.305-2.495)$ & $<0.001^{\mathrm{a}}$ & & \\
\hline \multicolumn{5}{|l|}{ Tumor stage } \\
\hline I & 1.000 (reference) & & 1.000 (reference) & \\
\hline II & $1.218(0.061-2.433)$ & 0.576 & $9.408(1.385-63.905)$ & 0.022 \\
\hline III & $2.788(1.748-4.444)$ & $<0.001^{\mathrm{a}}$ & $4.978(0.990-25.035)$ & 0.051 \\
\hline IV & $7.749(5.022-11.956)$ & $<0.001^{\mathrm{a}}$ & $12.099(2.650-55.037)$ & 0.001 \\
\hline \multicolumn{5}{|l|}{ T stage } \\
\hline $\mathrm{T} 1$ & 1.000 (reference) & & 1.000 (reference) & \\
\hline $\mathrm{T} 2$ & $1.547(0.884-2.706)$ & $0.126^{\mathrm{a}}$ & $0.109(0.019-0.639)$ & 0.014 \\
\hline $\mathrm{T} 3$ & $3.497(2.358-5.186)$ & $<0.001^{\mathrm{a}}$ & $0.358(0.078-1.650)$ & 0.188 \\
\hline $\mathrm{T} 4$ & $11.150(5.504-22.587)$ & $<0.001^{\mathrm{a}}$ & $0.334(0.063-1.784)$ & 0.200 \\
\hline \multicolumn{5}{|l|}{$\mathrm{N}$ stage } \\
\hline No & 1.000 (reference) & & 1.000 (reference) & \\
\hline N1 & & $<0.001^{\mathrm{a}}$ & & 0.493 \\
\hline \multicolumn{5}{|l|}{ M stage } \\
\hline M0 & 1.000 (reference) & & 1.000 (reference) & \\
\hline M1 & $4.882(3.523-6.765)$ & $<0.001^{\mathrm{a}}$ & $0.724(0.076-6.899)$ & 0.779 \\
\hline \multicolumn{5}{|l|}{ Histological stage } \\
\hline G1 & 1.000 (reference) & & & \\
\hline G2 & $2,448.345\left(0.000-6.607 \times 10^{37}\right)$ & 0.847 & & \\
\hline G3 & $4,767.788\left(0.000-1.286 \times 10^{38}\right)$ & 0.834 & & \\
\hline G4 & $13,172.972\left(0.000-3.554 \times 10^{38}\right)$ & 0.815 & & \\
\hline Laterality & & & 1.000 (reference) & \\
\hline Left & 1.000 (reference) & & & \\
\hline Right & $0.710(0.514-0.980)$ & $0.037^{\mathrm{a}}$ & $0.949(0.610-1.475)$ & 0.815 \\
\hline \multicolumn{5}{|c|}{ Primary treatment outcome } \\
\hline $\mathrm{CR}$ & 1.000 (reference) & & & \\
\hline PR & 0.000 & 0.997 & & \\
\hline SD & $6.667(1.777-25.014)$ & $0.005^{\mathrm{a}}$ & & \\
\hline PD & 0.000 & 0.989 & & \\
\hline \multicolumn{5}{|c|}{ Person neoplasm cancer status } \\
\hline Tumor-free & 1.000 (reference) & & 1.000 (reference) & \\
\hline With tumor & $6.140(4.284-8.800)$ & $<0.001^{\mathrm{a}}$ & $3.527(2.160-5.759)$ & $<0.001^{\mathrm{a}}$ \\
\hline \multicolumn{5}{|c|}{ Neoadjuvant treatment } \\
\hline Yes & 1.000 (reference) & & & \\
\hline No & $2.675(1.252-5.715)$ & $0.011^{\mathrm{a}}$ & & \\
\hline \multicolumn{5}{|l|}{ Hemoglobin result } \\
\hline Normal & 1.000 (reference) & & 1.000 (reference) & \\
\hline Low & $2.142(1.468-3.123)$ & $<0.001^{\mathrm{a}}$ & $1.588(0.983-2.565)$ & 0.059 \\
\hline Elevated & $5.471(1.682-17.798)$ & $0.011^{\mathrm{a}}$ & $6.386(0.838-48.686)$ & 0.074 \\
\hline
\end{tabular}


Table III. Continued.

Univariate analysis

Variables
Multivariate analysis

HR $(95 \%$ CI $)$

P-value

Serum calcium result

$\begin{array}{llll}\text { Normal } & 1.000 \text { (reference) } & & 1.000 \text { (reference) } \\ \text { Low } & 0.774(0.533-1.126) & 0.180 & \\ \text { Elevated } & 3.742(1.771-7.907) & 0.001^{\mathrm{a}} & 0.004\left(0.000-7.946 \times 10^{19}\right)\end{array}$

White cell count result
0.467
1.000 (reference)
Normal
$1.451(0.533-3.952)$
0.148
Elevated
$0.751(0.509-1.107)$

1.000 (reference)

Risk score

Low

1.000 (reference)

High

3.557 (2.443-5.178)

$<0.001^{\mathrm{a}}$

2.097 (1.264-3.478)

$0.004^{\mathrm{a}}$

$\mathrm{CR}$, complete remission; $\mathrm{PR}$, partial remission; $\mathrm{SD}$, stable disease; $\mathrm{PD}$, progressive disease.
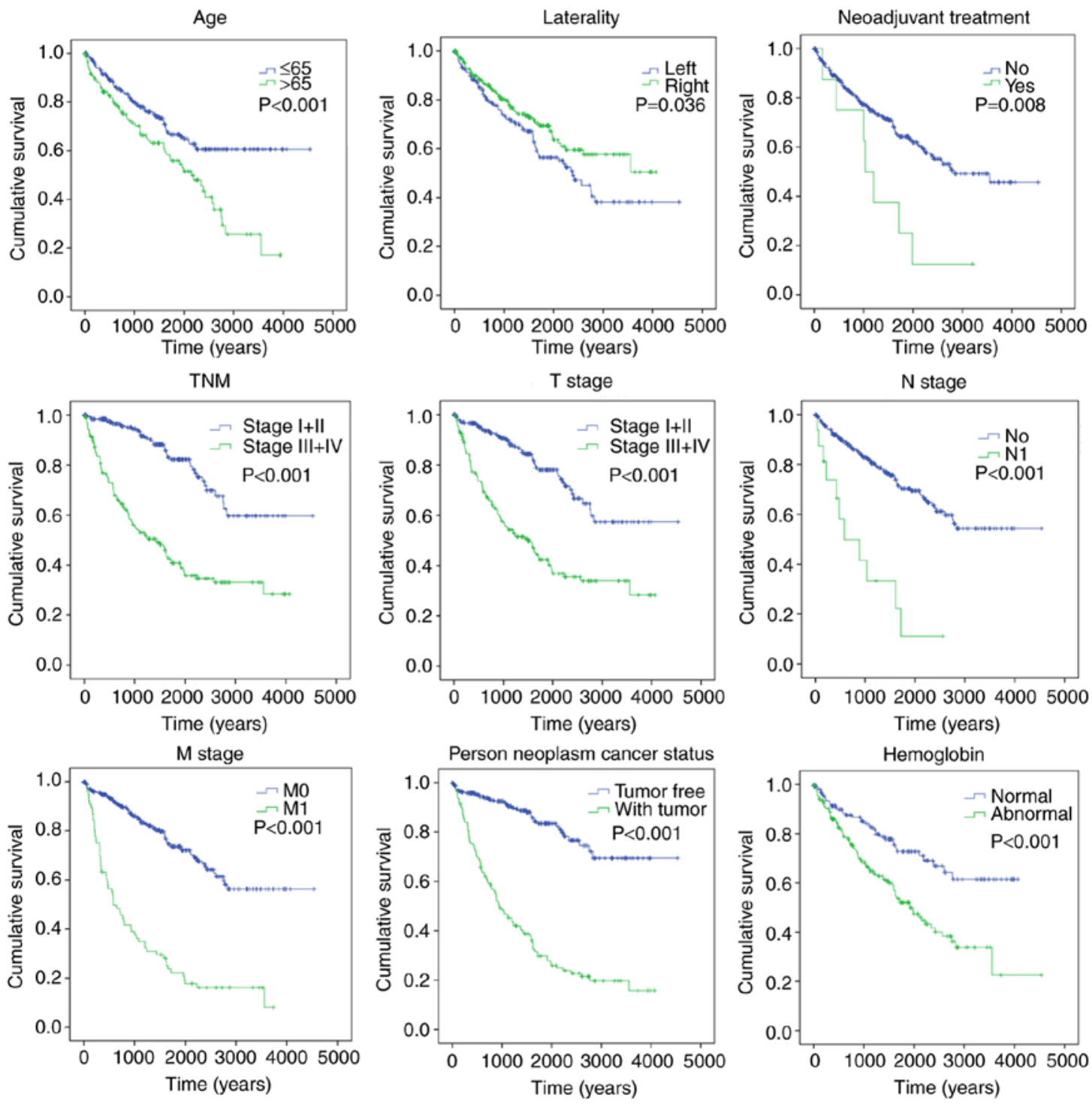

Figure 5. Prognostic value of different clinical features for overall survival of clear cell renal cell carcinoma patients. Kaplan-Meier curves of different clinical features. TNM, Tumor-Node-Metastasis. 

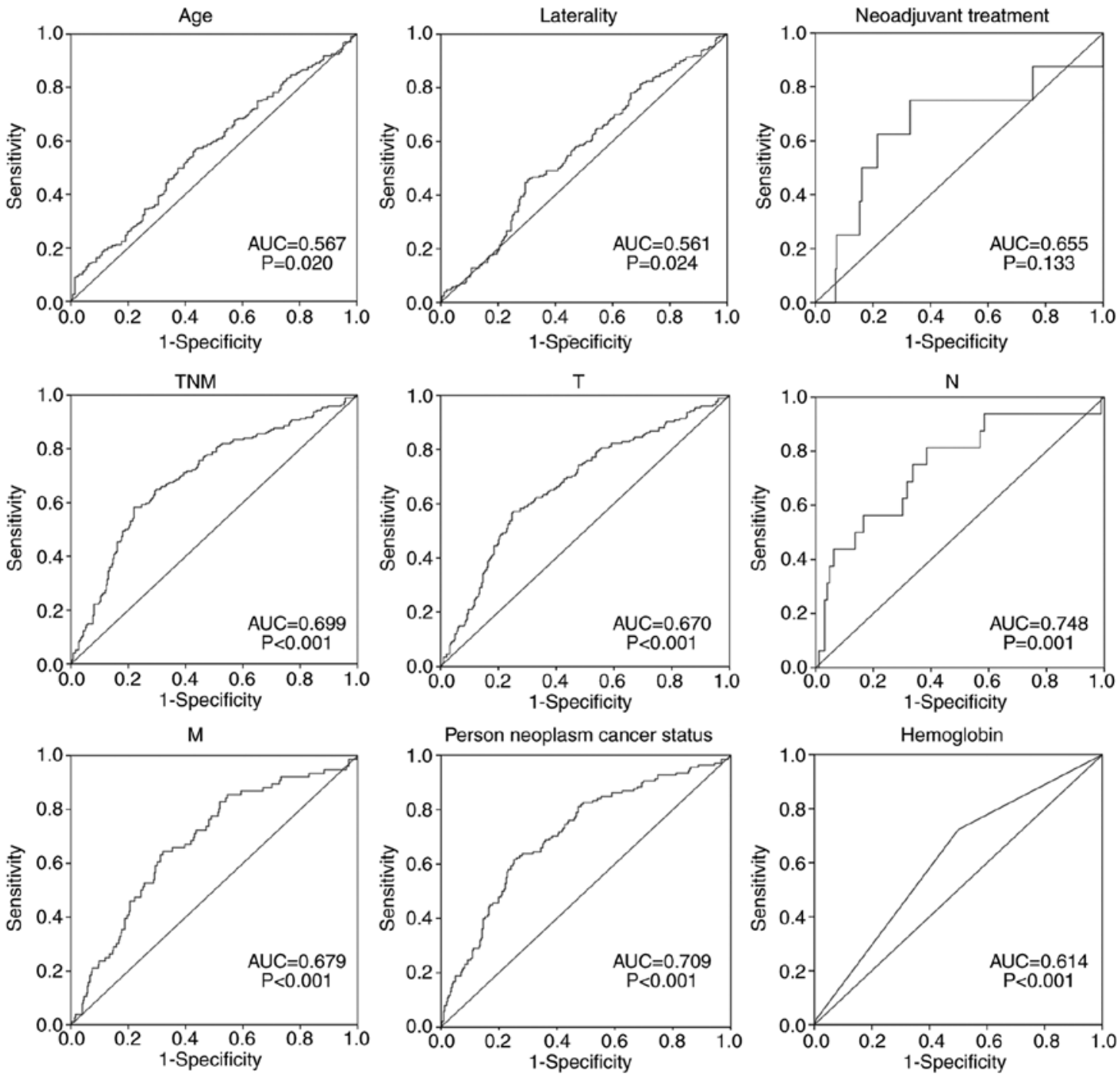

Figure 6. Predictive value of the risk score for clinical features of clear cell renal cell carcinoma patients. The receiver operating characteristic curve predicting different clinical features. TNM, Tumor-Node-Metastasis; AUC, area under the curve.

results demonstrated that these 5 lncRNAs (COL18A1-AS1, GK3P, TINCR, URB1-AS1 and ZNF542P) were consistently downregulated compared with those in the adjacent non-tumor tissue $(\mathrm{P}<0.05)$ (Fig. 8). The results suggested that there was a consistent trend of experimental verification and TCGA database analysis.

\section{Discussion}

$\mathrm{RCC}$ is one of the most common cancer types. In the United States, RCC causes nearly 64,000 new cancer cases and $>13,000$ mortalities annually (28). The early diagnosis and treatment of RCC have increased the prospects for patients, with a positive impact. Molecular markers can assist in improving the effectiveness of early diagnosis and prognosis prediction, although they have not yet become clinically routine (29). Recently, novel molecular markers have been investigated, and some of these markers show clinical prognostic potential. For example, mannosyl ( $\alpha$-1,6-)-glycoprotein $\beta$-1,6-N-acetyl-glu cosaminyltransferase is a potentially independent prognostic biomarker of patients with ccRCC subsequent to nephrectomy (30), and protocadherin 8 methylation is correlated with adverse clinical features (31). However, the majority of studies focus on a single biomarker or a small sample set. Based on a large dataset provided by TCGA public database, a large number of studies have evaluated the prognostic value of lncRNAs in various cancer types, including lung, gastric and breast cancer (32-34).

In the present study, a novel lncRNA signature for ccRCC prognosis was identified by screening differently expressed lncRNAs from four different groups of patients depending on tumor stages. Analysis of the univariate Cox proportional hazards regression models showed that 106 lncRNAs were significantly associated with OS time $(\mathrm{P}<0.05)$. Using the multivariate Cox proportional hazards regression analysis, 19 key lncRNAs were then identified $(\mathrm{P}<0.05)$ (LOC606724, SCART1, SNORA8, LOC728024, HAVCR1P1, FCGR1CP, LINC00240, LINC00894, GK3P, SNHG3, KIAA0125, URB1-AS1, ZNF542P, TINCR, LINC00926, PDXDC2P, COL18A1-AS1, LINC00202-1 and LINC00937). Next, an lncRNA prognostic signature was constructed based on a risk score model, which was a combination of the expression profiles of 19 lncRNAs weighted by the coefficients obtained by the multivariate Cox analysis. The results showed that 


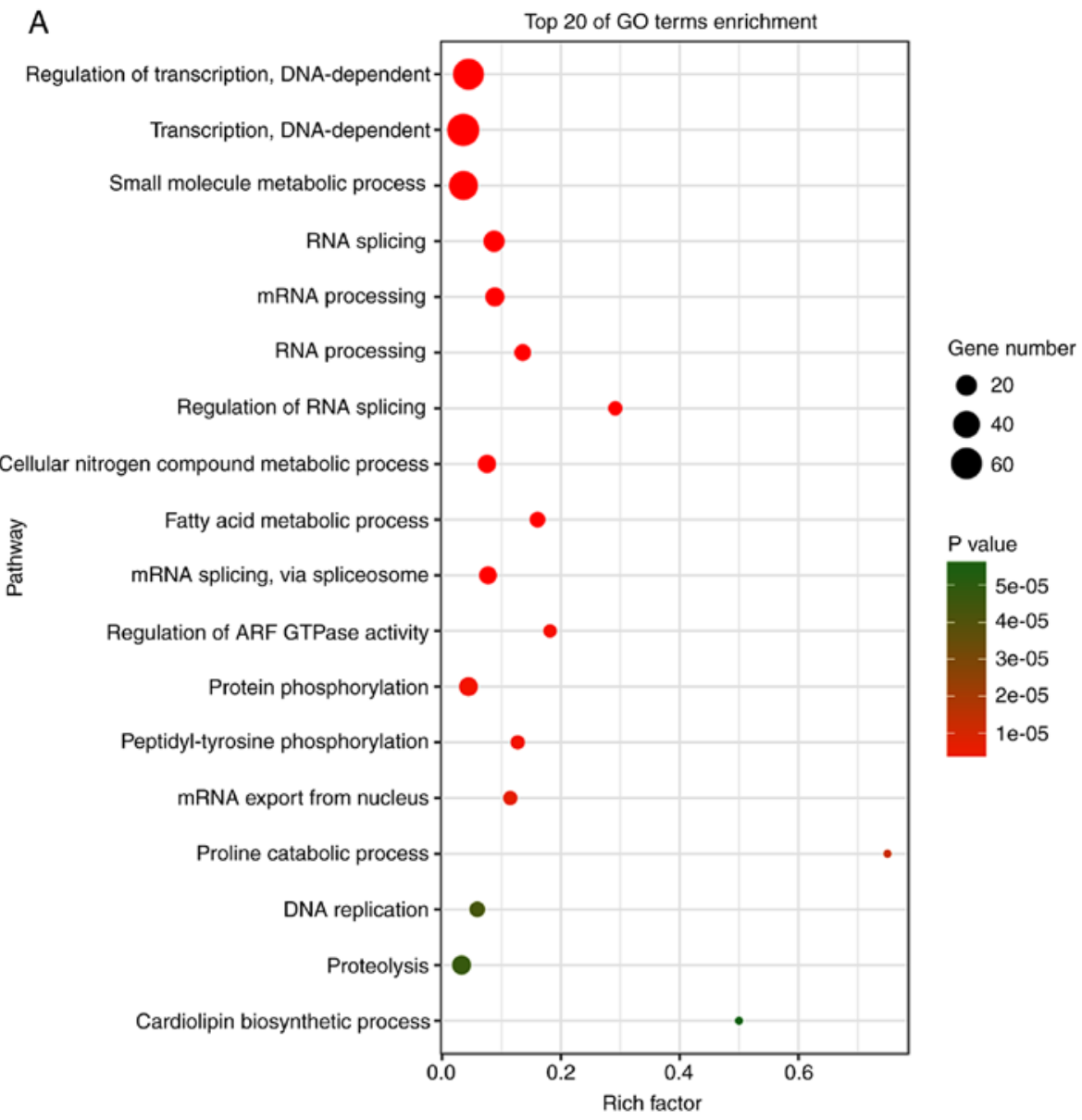

B

Top 20 of pathway enrichment

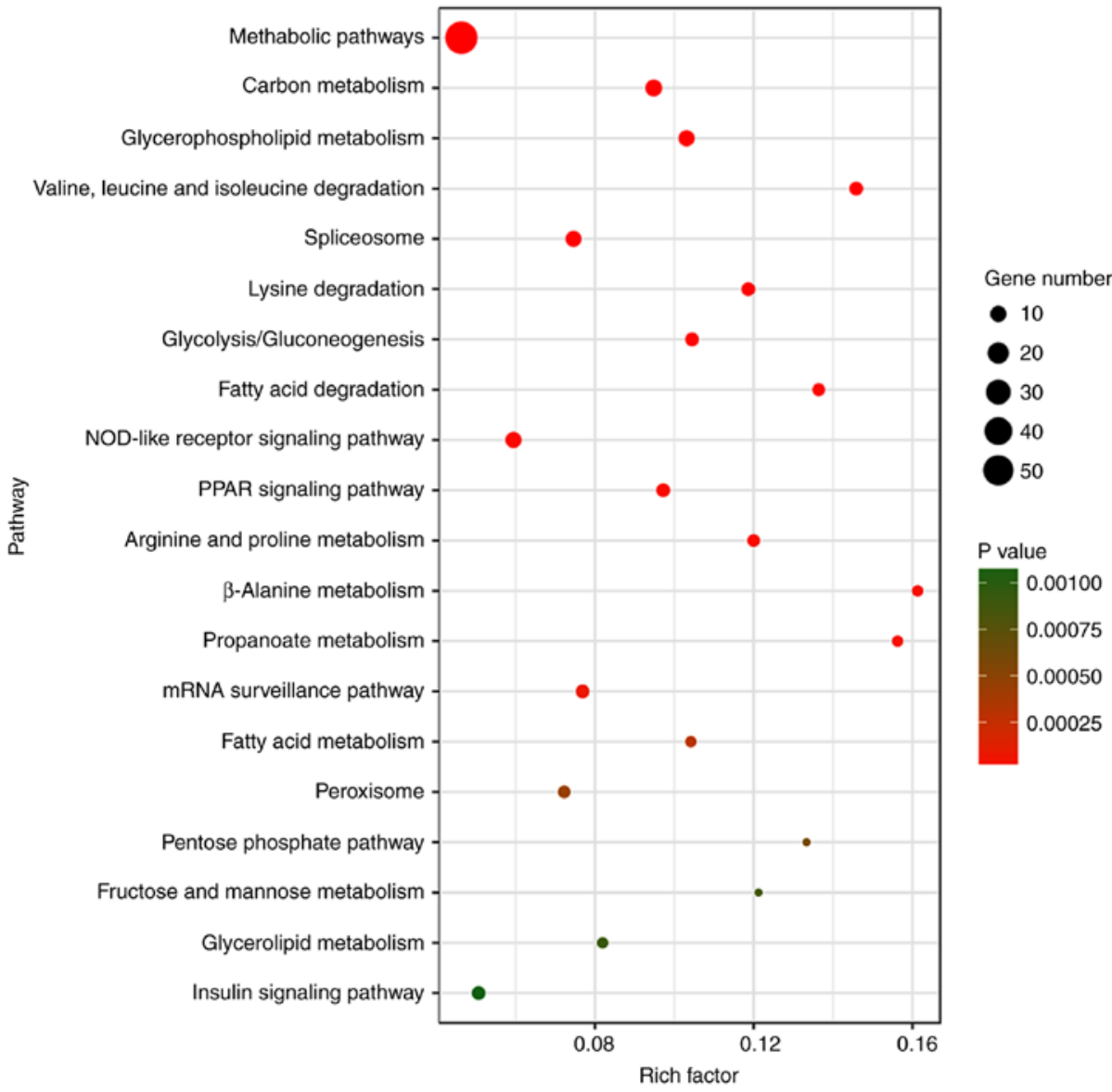

Figure 7. Top 20 enrichment of (A) GO terms and (B) Kyoto Encyclopedia of Genes and Genomes pathways for co-expressed genes. GO, Gene Ontology. 


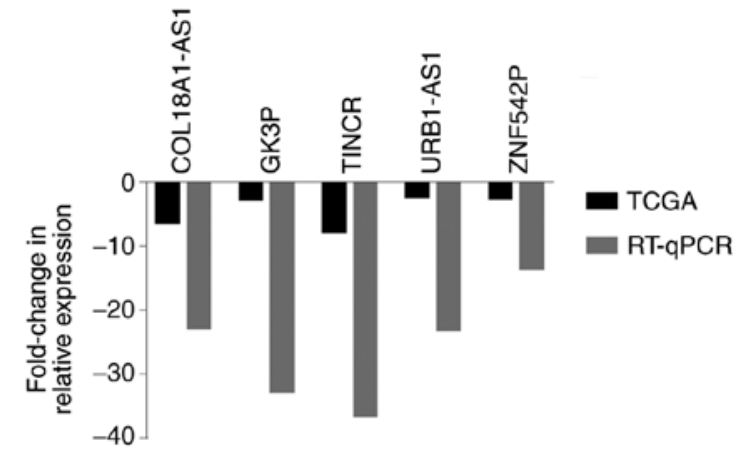

Figure 8. RT-qPCR verification of 5 long non-coding RNAs. TCGA, The Cancer Genome Atlas; RT-qPCR, reverse transcription-quantitative polymerase chain reaction.

this lncRNA tag could independently predict the OS time of patients with ccRCC. The efficacy of individual markers is limited, while multi-level markers could improve the prognostic value. The innovation of this study is tantamount to construct a risk score model and combine TCGA sequencing data with clinical features for comprehensive analysis. To the best of our knowledge, this is the first study to analyze not only lncRNAs associated with ccRCC prognosis using a risk score model, but also to include experimental validation.

The majority of previous studies have been based on the association between an individual lncRNA and ccRCC prognosis. Yao et al (35) used small interfering RNA to evaluate the biological function of CADM1-AS1 in vitro, and the results showed CADM1-AS1 to be a novel tumor suppressor in ccRCC. Using RT-qPCR, Xue et al (36) detected the expression pattern of NBAT-1 in patients with ccRCC and in renal cancer cell lines, and analyzed the correlation with clinicopathological features. The study found significantly decreased expression of NBAT-1 in the ccRCC tissues and renal cancer cells compared with that in the adjacent normal tissues, and that this low level was associated with advanced features and a poor prognosis. Also, a number of similar studies screened lncRNAs associated with tumor prognoses in ccRCC, including LOC389332, SPRY4-IT1 and MFI2-AS114 (15,37,38). One similar study screened 5 lncRNAs and constructed a signature of ccRCC (39). The difference is the fact that the present study screened for differently expressed lncRNAs based on the tumor stages compared with the adjacent non-tumor tissue. A risk scoring model was constructed based on each target lncRNA and combined TCGA sequencing data with clinical features for comprehensive analysis. Furthermore, RT-qPCR validation was performed on specimens from 17 ccRCC and paired adjacent non-tumor tissues, and the results showed the consistency of TCGA data analysis.

In the present study, a 19-IncRNA signature was identified based on IncRNA expression, and the prognostic power of this lncRNA signature was assessed by the time series ROC curve. The result of the risk score model indicated that this 19-IncRNA signature has independent prognostic value. Also, the function of these key lncRNAs is not completely understood. Therefore, genes were screened for that are closely associated with these key lncRNAs (Pearson $|R|>0.5$ ). These genes were mainly enriched in 'metabolic pathways', 'carbon metabolism' and 'glycerophospholipid metabolism'. These results may lay the groundwork for further studies.
The results of the present study may have potential clinical significance, but it cannot be denied that there are also certain limitations in this study. For example, the lncRNAs were identified through the tumor stage of ccRCC, but tumor metastasis was not considered. Due to the limited number of samples, further molecular studies of these lncRNAs are also lacking.

In conclusion, to the best of our knowledge, the present study is the first to use TCGA public database to identify and comprehensively analyze lncRNAs that are significantly associated with ccRCC prognosis. A 19-1ncRNA signature was identified and the joint prognostic power was evaluated, confirming this may be a potential biomarker for the prognosis of ccRCC. However, further studies are required to investigate the functions and molecular mechanisms of these lncRNAs in ccRCC.

\section{Acknowledgements}

The authors would like to thank Mr. Donglin Cheng from Nanjing Genemap Co., Ltd., (Nanjing, Jiangsu, China) for providing technical assistance to the project.

\section{Funding}

The present study was supported by the National Natural Science Foundation of China (grant nos. 81673132 and 81472939), the Scientific Research Foundation of Graduate School of Southeast University (YBJJ1796), and the Fundamental Research Funds for the Central Universities and Innovative Research Project for postgraduates in Colleges of Jiangsu province.

\section{Availability of data and materials}

The datasets generated and analyzed during the current study are available in TCGA repository (http://cancergenome.nih.gov).

\section{Authors' contributions}

TL and GYL conceived and designed the study. TL and JS performed the experiments. YZ and XMZ performed tissue sample collection for patients with ccRCC. WJW, SY, SYX, WWH, HP analyzed and interpreted the results. LHY and YPP assisted with study design and provided advice. TL performed analysis and quality control, and was a major contributor in writing the manuscript. All authors read and approved the final manuscript.

\section{Ethics approval and consent to participate}

All procedures performed in the study that involved human participants were in accordance with the ethical standards of the institutional and national research committee and with the 1964 Helsinki declaration and its later amendments or comparable ethical standards.

\section{Patient consent for publication}

Informed consent was obtained from all individual participants included in the study. 


\section{Competing interests}

The authors declare that they have no competing interests.

\section{References}

1. Capitanio U and Montorsi F: Renal cancer. Lancet 387: 894-906, 2015.

2. Ferlay J, Shin HR, Bray F, Forman D, Mathers C and Parkin DM: Estimates of worldwide burden of cancer in 2008: GLOBOCAN 2008. Int J Cancer 127: 2893-2917, 2010.

3. Siegel RL, Miller KD and Jemal A: Cancer statistics, 2015. CA Cancer J Clin 65: 5-29, 2015.

4. Baldewijns MM, van Vlodrop IJ, Schouten LJ, Soetekouw PM, de Bruïne AP and van Engeland M: Genetics and epigenetics of renal cell cancer. Biochim Biophys Acta 1785: 133-155, 2008.

5. Arsanious A, Bjarnason GA and Yousef GM: From bench to bedside: Current and future applications of molecular profiling in renal cell carcinoma. Mol cancer 8: 20, 2009.

6. Cohen HT and McGovern FJ: Renal-cell carcinoma. N Engl J Med 353: 2477-2490, 2005

7. Lam JS, Shvarts O, Leppert JT, Pantuck AJ, Figlin RA and Belldegrun AS: Postoperative surveillance protocol for patients with localized and locally advanced renal cell carcinoma based on a validated prognostic nomogram and risk group stratification system. J Urol 174: 466-472; quiz 801, 2005.

8. Tsui KH, Shvarts O, Smith RB, Figlin RA, deKernion JB and Belldegrun A: Prognostic indicators for renal cell carcinoma: A multivariate analysis of 643 patients using the revised 1997 TNM staging criteria. J Urol 163: 1090-1095; quiz 1295, 2000.

9. Thompson RH, Gillett MD, Cheville JC, Lohse CM, Dong H, Webster WS, Krejci KG, Lobo JR, Sengupta S, Chen L, et al: Costimulatory B7-H1 in renal cell carcinoma patients: Indicator of tumor aggressiveness and potential therapeutic target. Proc Natl Acad Sci USA 101: 17174-17179, 2004.

10. Harshman LC, Choueiri TK, Drake C and Stephen Hodi F Jr: Subverting the B7-H1/PD-1 pathway in advanced melanoma and kidney cancer. Cancer J 20: 272-280, 2014.

11. Thompson RH and Kwon ED: Significance of B7-H1 overexpression in kidney cancer. Clinical Genitourin Cancer 5: 206-211, 2006.

12. Chandra Gupta S and Nandan Tripathi Y: Potential of long non-coding RNAs in cancer patients: From biomarkers to therapeutic targets. Int J Cancer 140: 1955-1967, 2017.

13. Wang L, Cai Y, Zhao X, Jia X, Zhang J, Liu J, Zhen H, Wang T, Tang X, Liu Y, et al: Down-regulated long non-coding RNA H19 inhibits carcinogenesis of renal cell carcinoma. Neoplasma 62: $412-418,2015$

14. Hirata H, Hinoda Y, Shahryari V, Deng G, Nakajima K, Tabatabai ZL, Ishii $\mathrm{N}$ and Dahiya R: Long noncoding RNA MALAT1 promotes aggressive renal cell carcinoma through Ezh2 and interacts with miR-205. Cancer Res 75: 1322-1331, 2015.

15. Zhang HM, Yang FQ, Yan Y, Che JP and Zheng JH: High expression of long non-coding RNA SPRY4-IT1 predicts poor prognosis of clear cell renal cell carcinoma. Int J Clin Exp Pathol 7: 5801-5809, 2014.

16. Song S, Wu Z, Wang C, Liu B, Ye X, Chen J, Yang Q, Ye H, Xu B and Wang L: RCCRT1 is correlated with prognosis and promotes cell migration and invasion in renal cell carcinoma. Urology 84 730.e1-e7, 2014.

17. Li CY, Liang GY, Yao WZ, Sui J, Shen X, Zhang YQ, Peng H, Hong WW, Ye YC, Zhang ZY, et al: Identification and functional characterization of microRNAs reveal a potential role in gastric cancer progression. Clin Transl Oncol 19: 162-172, 2017.

18. Chan AC, Fan ST, Poon RT, Cheung TT, Chok KS, Chan SC and Lo CM: Evaluation of the seventh edition of the American Joint Committee on Cancer tumour-node-metastasis (TNM) staging system for patients undergoing curative resection of hepatocellular carcinoma: Implications for the development of a refined staging system. HPB 15: 439-448, 2013

19. Sui J, Li YH, Zhang YQ, Li CY, Shen X, Yao WZ, Peng H, Hong WW, Yin LH, Pu YP, et al: Integrated analysis of long non-coding RNAassociated ceRNA network reveals potential lncRNA biomarkers in human lung adenocarcinoma. Int $\mathrm{J}$ Oncol 49: 2023-2036, 2016

20. Miao Y, Sui J, Xu SY, Liang GY, Pu YP and Yin LH: Comprehensive analysis of a novel four-lncRNA signature as a prognostic biomarker for human gastric cancer. Oncotarget 8: 75007-75024, 2017.
21. Zeng JH, Liang L, He RQ, Tang RX, Cai XY, Chen JQ, Luo DZ and Chen G: Comprehensive investigation of a novel differentially expressed lncRNA expression profile signature to assess the survival of patients with colorectal adenocarcinoma. Oncotarget 8: 16811-16828, 2017.

22. Zhao Q and Sun J: Cox survival analysis of microarray gene expression data using correlation principal component regression. Stat Appl Genet Mol Biol 6: Article 16, 2007.

23. Zhou X, Huang Z, Xu L, Zhu M, Zhang L, Zhang H, Wang X, $\mathrm{Li} \mathrm{H}$, Zhu W, Shu Y, et al: A panel of 13-miRNA signature as a potential biomarker for predicting survival in pancreatic cancer. Oncotarget 7: 69616-69624, 2016.

24. Heagerty PJ, Lumley T and Pepe MS: Time-dependent ROC curves for censored survival data and a diagnostic marker. Biometrics 56: 337-344, 2000.

25. Liu Z, Shao W, Shen Y, Ji M, Chen W, Ye Y and Shen Y: Characterization of new microsatellite markers based on the transcriptome sequencing of Clematis finetiana. Hereditas 155: 23, 2018.

26. Sho S, Court CM, Winograd P, Russell MM and Tomlinson JS: A prognostic mutation panel for predicting cancer recurrence in stages II and III colorectal cancer. J Surg Oncol 116: 996-1004, 2017.

27. Livak KJ and Schmittgen TD: Analysis of relative gene expression data using real-time quantitative PCR and the $2^{-\Delta \Delta C \mathrm{~T}}$ method. Methods 25: 402-408, 2001.

28. Krishnan B, Rose TL, Kardos J, Milowsky MI and Kim WY: Intrinsic genomic differences between African American and white patients with clear cell renal cell carcinoma. JAMA Oncol: Mar 24, 2016 (Epub ahead of print). doi: 10.1001/jamaoncol.2016.0005

29. Eichelberg C, Junker K, Ljungberg B and Moch H: Diagnostic and prognostic molecular markers for renal cell carcinoma: A critical appraisal of the current state of research and clinical applicability. Eur Urol 55: 851-863, 2009.

30. Liu Y, Liu H, Liu W, Zhang W, An H and Xu J: $\beta 1,6-N$-acetyl glucosaminyltransferase $\mathrm{V}$ predicts recurrence and survival of patients with clear-cell renal cell carcinoma after surgical resection. World J Urol 33: 1791-1799, 2015.

31. Lin YL, Wang YL, Fu XL and Ma JG: Aberrant methylation of PCDH8 is a potential prognostic biomarker for patients with clear cell renal cell carcinoma. Med Sci Monit 20: 2380-2385, 2014.

32. Zhang Y, Wang DL, Yan HY, Liao JY, He JH, Hu KS, Deng WX, Wang YJ, Xing HT, Koeffler HP, et al: Genome-wide study of ER-regulated lncRNAs shows AP000439.3 may function as a key regulator of cell cycle in breast cancer. Oncol Rep 38: 3227-3237, 2017.

33. Li CY, Liang GY, Yao WZ, Sui J, Shen X, Zhang YQ, Peng H, Hong WW, Ye YC, Zhang ZY, et al: Integrated analysis of long non-coding RNA competing interactions reveals the potential role in progression of human gastric cancer. Int $\mathrm{J}$ Oncol 48: 1965-1976, 2016.

34. Zheng S, Zheng D, Dong C, Jiang J, Xie J, Sun Y and Chen H: Development of a novel prognostic signature of long non-coding RNAs in lung adenocarcinoma. J Cancer Res Clin Oncol 143: 1649-1657, 2017.

35. Yao J, Chen Y, Wang Y, Liu S, Yuan X, Pan F and Geng P: Decreased expression of a novel lncRNA CADM1-AS1 is associated with poor prognosis in patients with clear cell renal cell carcinomas. Int J Clin Exp Pathol 7: 2758-2767, 2014.

36. Xue S, Li QW, Che JP, Guo Y, Yang FQ and Zheng JH: Decreased expression of long non-coding RNA NBAT-1 is associated with poor prognosis in patients with clear cell renal cell carcinoma. Int J Clin Exp Pathol 8: 3765-3774, 2015.

37. Flippot R, Mouawad R, Spano JP, Rouprêt M, Compérat E, Bitker MO, Parra J, Vaessen C, Allanic F, Manach Q, et al: Expression of long non-coding RNA MFI2-AS1 is a strong predictor of recurrence in sporadic localized clear-cell renal cell carcinoma. Sci Rep 7: 8540, 2017.

38. Jin P, Wang J and Liu Y: Downregulation of a novel long non-coding RNA, LOC389332, is associated with poor prognosis and tumor progression in clear cell renal cell carcinoma. Exp Ther Med 13: 1137-1142, 2017.

39. Shi D, Qu Q, Chang Q, Wang Y, Gui Y and Dong D: A five-long non-coding RNA signature to improve prognosis prediction of clear cell renal cell carcinoma. Oncotarget 8: 58699-58708, 2017. 